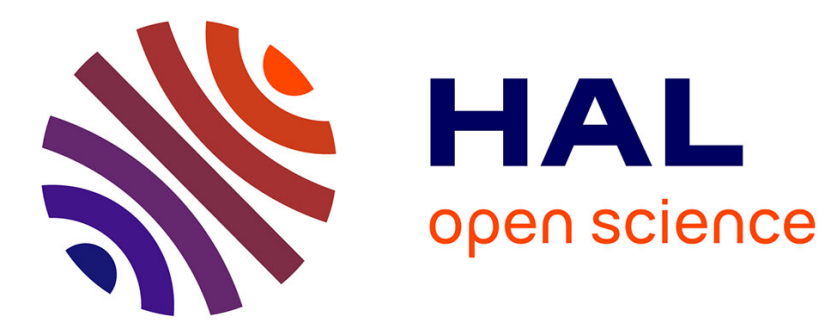

\title{
Formation of artificial ionospheric ducts
}

G.M. Milikh, K Papadopoulos, H Shroff, C.L. Chang, T Wallace, E.V. Mishin, Michel Parrot, Jean-Jacques Berthelier

\section{To cite this version:}

G.M. Milikh, K Papadopoulos, H Shroff, C.L. Chang, T Wallace, et al.. Formation of artificial ionospheric ducts. Geophysical Research Letters, 2008, 35, pp.L17104. 10.1029/2008GL034630 . insu-01253625

\section{HAL Id: insu-01253625 \\ https://hal-insu.archives-ouvertes.fr/insu-01253625}

Submitted on 11 Jan 2016

HAL is a multi-disciplinary open access archive for the deposit and dissemination of scientific research documents, whether they are published or not. The documents may come from teaching and research institutions in France or abroad, or from public or private research centers.
L'archive ouverte pluridisciplinaire HAL, est destinée au dépôt et à la diffusion de documents scientifiques de niveau recherche, publiés ou non, émanant des établissements d'enseignement et de recherche français ou étrangers, des laboratoires publics ou privés. 


\title{
Formation of artificial ionospheric ducts
}

\author{
G. M. Milikh, ${ }^{1}$ K. Papadopoulos, ${ }^{1}$ H. Shroff, ${ }^{1}$ C. L. Chang, ${ }^{2}$ T. Wallace, ${ }^{2}$ E. V. Mishin, ${ }^{3}$ \\ M. Parrot, ${ }^{4}$ and J. J. Berthelier ${ }^{5}$ \\ Received 8 May 2008; revised 28 July 2008; accepted 6 August 2008; published 13 September 2008.
}

[1] It is well known that strong electron heating by a powerful HF-facility can lead to the formation of electron and ion density perturbations that stretch along the magnetic field line. Those density perturbations can serve as ducts for ELF waves, both of natural and artificial origin. This paper presents the first experimental evidence of plasma modifications associated with ion outflows due to $\mathrm{HF}$ heating. The experiments were conducted using the HAARP heater during times that the DEMETER satellite flying at an altitude of approximately $670 \mathrm{~km}$ was close to the magnetic zenith of HAARP. The DEMETER satellite has provided in situ measurements of the ion temperature and composition. The experimental results are compared with the numerical model of inter-hemispheric artificial ducts, and it is found that they are in qualitative agreement. Citation: Milikh, G. M., K. Papadopoulos, H. Shroff, C. L. Chang, T. Wallace, E. V. Mishin, M. Parrot, and J. J. Berthelier (2008), Formation of artificial ionospheric ducts, Geophys. Res. Lett., 35, L17104, doi:10.1029/2008GL034630.

\section{Introduction}

[2] It is well known that the presence of field aligned density striations plays a critical role in the propagation of whistler waves in the ionosphere [see, e.g., Streltsov et al., 2006]. These density structures serve as ducts for VLF/ELF waves as the density gradient perpendicular to the magnetic field leads to their total internal reflection. Such density structures has often been observed [Carpenter et al., 2002] to extend over distances covering entire magnetic field lines, trapping, channeling and reflecting whistler waves across conjugate regions. In fact, the presence of such ducts is often considered as a pre-requisite to the generation of Artificially Stimulated Emissions (ASE) such as have been extensively studied by using the Siple VLF transmitter [Helliwell, 1988], as well as more recently by the HAARP heater [Inan et al., 2004]. In the HAARP case the VLF waves were generated by modulating the auroral electrojet current at VLF frequencies [see, e.g., Papadopoulos et al., 2003, 2005; Ferraro et al., 1989; Barr and Stubbe, 1993].

[3] The possibility for artificially creating such transhemispheric ducts was first discussed by Perrine et al.

\footnotetext{
${ }^{1}$ Department of Astronomy, University of Maryland, College Park, Maryland, USA.

${ }^{2}$ BAE Systems, Washington, DC, USA.

${ }^{3}$ Institute for Scientific Research, Boston College, Chestnut Hill, Massachusetts, USA.

${ }^{4}$ Laboratoire de Physique et Chimie de l'Environnement, CNRS, Orleans, France.

${ }^{5}$ IPSL, CETP, St. Maur, France.
}

Copyright 2008 by the American Geophysical Union. 0094-8276/08/2008GL034630
[2006]. In this paper it was shown that long term ( $>15$ minutes) continuous HF-heating of the F-region by powerful ionospheric heaters such as HAARP generates a strong heat transport in the ionospheric and magnetospheric plasma, which is often called a "thermal wave". This thermal wave propagates along the magnetic field line through the topside ionosphere and magnetosphere, driving ion outflows, displacing the ambient plasma and leading to the formation of density ducts that stretch along the magnetic field line to the conjugate point. We should mention that upward ion flows from the ionosphere such as the ones predicted by the model were detected by satellites [Shelley et al., 1976], as well as by the EISCAT incoherent radar [Wahlund et al., 1992]. They are ascribed to frictional ion heating by perpendicular electric fields in the ionosphere. Within our concept the frictional heating is replaced by artificial heating using the HAARP facility.

[4] It is the objective of this letter to present the first experimental evidence of plasma modifications associated with ion outflows due to HF heating. The experiments were conducted using the HAARP heater during times that the DEMETER satellite flying at an altitude of approximately $670 \mathrm{~km}$ was close to the magnetic zenith of HAARP, defined at the satellite altitude as the center of the magnetic tube intersecting the heated region in the ionosphere. The DEMETER satellite [Parrot, 2002] provided in situ measurements of the ion temperature and composition.

[5] The letter is organized as following: the next section briefly reviews the theoretical/computational model and its predictions. Section 3 describes the results of the joint HAARP/DEMETER heating experiments. The final section compares the experimental results with the model predictions and discusses their relevance.

\section{Global Ionospheric Heating Model}

[6] The theoretical/computational modeling is utilized by SAMI2 code which has been developed at the Naval Research Laboratory [Huba et al., 2000]. The code is an Eulerian grid-based code, which describes the ionosphere made up of 7 ion species. The equations of continuity and momentum are solved for the electrons and each ion species, with the temperature equation solved for the electrons and the species $\mathrm{H}^{+}, \mathrm{He}^{+}$, and $\mathrm{O}^{+}$. Electron density is determined on the basis of charge neutrality. The code includes $E x \quad x \quad B$ drift of the field lines (in altitude and longitude), a neutral atmosphere model, horizontal winds, photo-deposition into the ionosphere, ion chemistry models, and ion inertia. The inclusion of ion inertia is critical since allows for the study of sound wave propagation in the plasma. The SAMI2 model is inter-hemispheric and can thus simulate the plasma along entire magnetic dipole field 


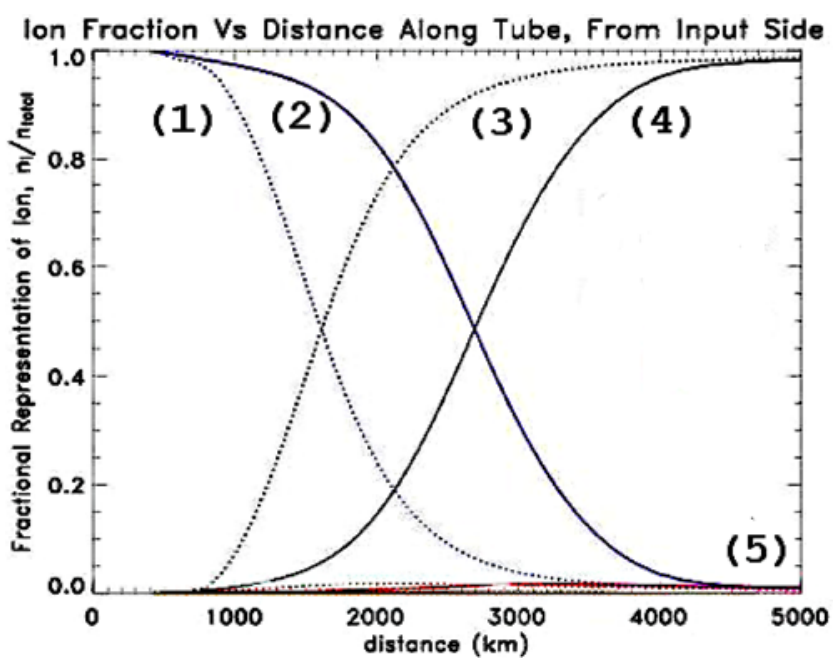

Figure 1. Predicted changes in ion composition above the heated region during artificial heating. The vertical axis is the fraction of the total ion number density that is a single species, with traces (1) and (2) representing $\mathrm{O}^{+}$, and traces (3) and (4) representing $\mathrm{H}^{+}$under both ambient and heated conditions, respectively. $\mathrm{He}^{+}$which is weakly affected by the ionospheric heating, is shown by the trace (5). This plot represents the system after 15 minutes of HF-heating. Heating parameters for this data: $q=5000 \mathrm{~K} / \mathrm{s}, z_{0}=380 \mathrm{~km}$.

lines. Note that the version of SAMI2 used in this study is limited to mid and low latitudes.

[7] In order to study formation of artificial ducts due to HF-heating SAMI was modified to include a localized flexible source of heating [Perrine et al., 2006]. In addition to Joule heating from electron-ion and electron-neutral collisions and photoelectron heating we include the electron temperature term, representing the HF artificial heating. This term is represented by a Gaussian shaped source given by:

$$
\begin{gathered}
Q(K / s)=q \exp \left\{-\left(z-z_{0}\right)^{2} / a^{2}\right\} \\
q=\eta W / V n_{e}
\end{gathered}
$$

[8] Here Q refers to the total heating rate per electron (in Kelvin per second) delivered to location $\mathrm{z}$. The parameters of this term are the altitude of the heated spot's center $z_{0}$, vertical extent of the heated region $\mathrm{z}$, and the heating rate per electron q, which in turn is determined by the radiated HF power $\mathrm{W}$, wave absorption coefficient $\eta$, HF-heated volume $\mathrm{V}$, and ambient electron number density $\mathrm{n}_{\mathrm{e}}$. In fact, for current HAARP the heating rate reaches $5,000 \mathrm{~K} / \mathrm{s}$.

[9] The height of the heated spot $\left(\mathrm{z}_{0}\right)$ is determined by the HF frequency of the heater, and the vertical extent of the region $(a)$ is determined by the plasma frequency of that altitude $\left(\omega_{\mathrm{e}}\right)$ and the electron cyclotron frequency $\left(\Omega_{\mathrm{e}}\right)$. It has been shown that strong wave absorption occurs in a relatively thin region $(10-20 \mathrm{~km})$ between the wave reflection point and the location of the upper hybrid resonance (where $\omega=\sqrt{\omega_{e}^{2}+\Omega_{e}^{2}}$ ). This region is filled with irregularities induced by the HF-heating, that converts the HF wave to electrostatic wave leading to the so called "anomalous absorption" [Stubbe et al., 1994; Gurevich et al., 1996].

[10] A decrease in the electron density which occurs in the heated region [see, e.g., Duncan et al., 1988] leads to the plasma motion along the field line due to ambipolar diffusion. It results in non-uniform motion of the plasma species. Figures 1 and 2 show the variation of ion composition with altitude and of the corresponding ion temperature after 15 minutes of HF-heating obtained from a simulation with the following parameters: $q=5000 \mathrm{~K} / \mathrm{s}$, $\mathrm{z}_{0}=380 \mathrm{~km}$. It can be seen that the dominant ion at low altitudes, $\mathrm{O}^{+}$, rises up quickly during heating to enhance the density at higher altitudes, resulting in a change in the ion composition while the ion temperature almost doubles at a few hundred kilometers above the heated region, following 15 minutes of continuous heating. Since the code is one dimensional the formation of density gradients is implied, but cannot be seen in Figures 1 and 2 .

\section{Experiments}

[11] A number of experimental tests were conducted following the completion of the HAARP heater in 2007. In all of the tests the transmitted power was 3.6 MW, Omode and the beam was directed along the HAARP magnetic zenith. The modified ionosphere was sensed by two instruments on-board of Demeter, the ICE detector that measures the ionospheric electric field vectors, and the plasma analyzer that measures the ion temperature and composition $\left(\mathrm{O}^{+}, \mathrm{H}^{+}, \mathrm{He}^{+}\right)$[Berthelier et al., 2006a, 2006b]. We report below on cases corresponding to DEMETER-HAARP zenith closest approach less than $300 \mathrm{~km}$. We identified five such cases during our experimental time. However, in two of those cases the $\mathrm{F}_{2}$-layer critical frequency, $\mathrm{f}_{0} \mathrm{~F}_{2}$, was much lower than the frequency available from the transmitter resulting in very weak absorption and no detectable effects.

[12] Table 1 describes the heater and ionospheric parameters for the remaining three cases. During the transmission and to accommodate a different experiment the transmitter was modulated by ULF frequency. The effect of the modulation was to reduce the effective constant wave power by a factor of approximately two.

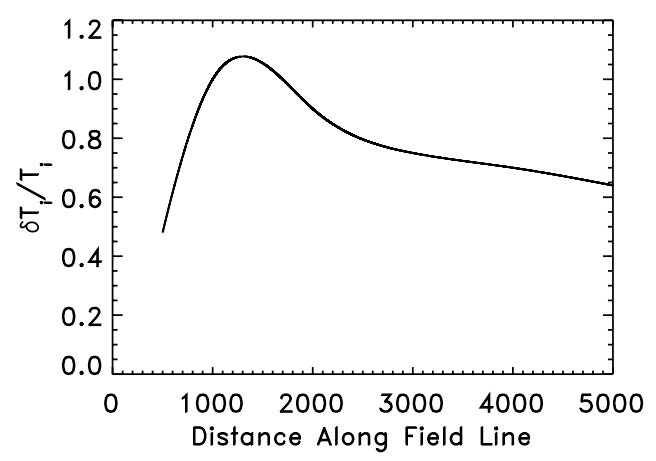

Figure 2. Changes in ion temperature above the heated region during artificial heating. Computed at the same conditions as in Figure 1. 
Table 1. List of the Heater and Ionospheric Parameters Along With the Closest Approach ${ }^{\mathrm{a}}$

\begin{tabular}{cccccc}
\hline Date & Time (UT) & $\mathrm{f}_{0} \mathrm{~F}_{2}(\mathrm{MHz})$ & HF Frequency $(\mathrm{MHz})$ & ERP $(\mathrm{MW})$ & Closest Approach $(\mathrm{km})$ \\
\hline 4/24/07 & $06: 26: 30-06: 59: 30$ & 3.8 & 3.2 & 370 & 55 \\
$8 / 01 / 07$ & $06: 42: 00-06: 52: 00$ & 3.0 & 2.85 & 280 & 94 \\
$8 / 24 / 07$ & $06: 55: 00-07: 15: 00$ & 3.8 & 3.3 & 410 & 137 \\
\hline
\end{tabular}

${ }^{\mathrm{a}}$ Distance of DEMETER to HAARP in the experiments discussed.

[13] In all of the above cases the on-site HAARP diagnostics indicated a smooth F-region layer, negligible D/E region absorption and absence of electrojet current. Figures 3 and 4 show key measurements made during two of the above DEMETER passes, 4/24/07 and 8/01/07. Figure 3 shows ion temperature and density profiles for the first case of Table 1 . Both the ion temperature and $\mathrm{O}^{+}$ density rise due to the HF-heating by about $60-70 \%$. The rise of the temperature and density was detected over 3-4 minutes corresponding to $1,300-1,700 \mathrm{~km}$ distances. Reduction in the $\mathrm{H}^{+}$density correlated with the heating was also observed (not shown here) near the closest approach. The temperature peak occurs one minute earlier than the density. That corresponds to a lateral shift of approximately $480 \mathrm{~km}$. Notice also a spatial asymmetry of the ion outflows directed towards the incoming satellite (see Figure 3). Notice the presence of a duct associated with the density gradient between 06:51:00 and 06:51:30 (marked by (1) in Figure 3), the presence of a cavity between 06:54:30 and 06:55:00 (marked by (3)), as well as a series of few percent short length ducts between 06:52:00 and 06:53:30 (marked by (2)). The latter correspond to magnetosonic waves at the $0.1 \mathrm{~Hz}$ modulation and are correlated with simultaneous detection of $0.1 \mathrm{~Hz}$ oscillations in both horizontal components of the electric field in the region of closest approach. They will be examined in a future publication.
[14] Figure 4 corresponds to the second case of Table 1. It shows a sharp peak of $\mathrm{T}_{\mathrm{i}}\left(\delta \mathrm{T}_{\mathrm{i}} / \mathrm{T}_{\mathrm{i}}^{\mathrm{o}} \simeq 2\right)$, and $\mathrm{n}_{\mathrm{i}}\left(\delta \mathrm{n}_{\mathrm{i}} / \mathrm{n}_{\mathrm{i}}^{\mathrm{o}} \simeq 2.5\right)$, caused by the ion outflows. These two peaks are shifted by $1 \mathrm{~min}(480 \mathrm{~km})$. Furthermore starting at 6:47:10 a strong increase of $\mathrm{O}^{+}$density occurs along with the increase of $\mathrm{H}^{+}$ and $\mathrm{He}^{+}$. The magnetometer data reveal a sharp peak at this time. We attribute this to the occurrence of natural ion precipitation. In fact, data obtained from the DMSP F16 satellite indicate the presence of strong precipitation at latitude of $66^{\circ}$ and higher where Demeter moved at this time. Therefore the increase in $\mathrm{O}^{+}$density due to HFheating was masked by the precipitation.

[15] Third case of Table 1 is similar to the second one (the figure is not presented). We detected increase in $T_{i}$ and $\mathrm{O}^{+}$density due to HF-heating $\left(\delta \mathrm{T}_{\mathrm{i}} / \mathrm{T}_{\mathrm{i}}^{\mathrm{o}} \simeq 0.3, \delta \mathrm{n}_{\mathrm{i}} / \mathrm{n}_{\mathrm{i}}^{\mathrm{o}} \simeq 1.0\right)$. Reduction of the $\mathrm{H}^{+}$and $\mathrm{He}^{+}$was also observed. Similarly to the second case the natural ion precipitation occurred at the late stage of these observations as revealed by the DMSP F16 satellite, which led to the ion density perturbations.

\section{Discussion}

[16] We presented the first experimental verification of strong ion outflows and formation of the ionospheric ducts by F-region ionospheric heating. Their generation requires

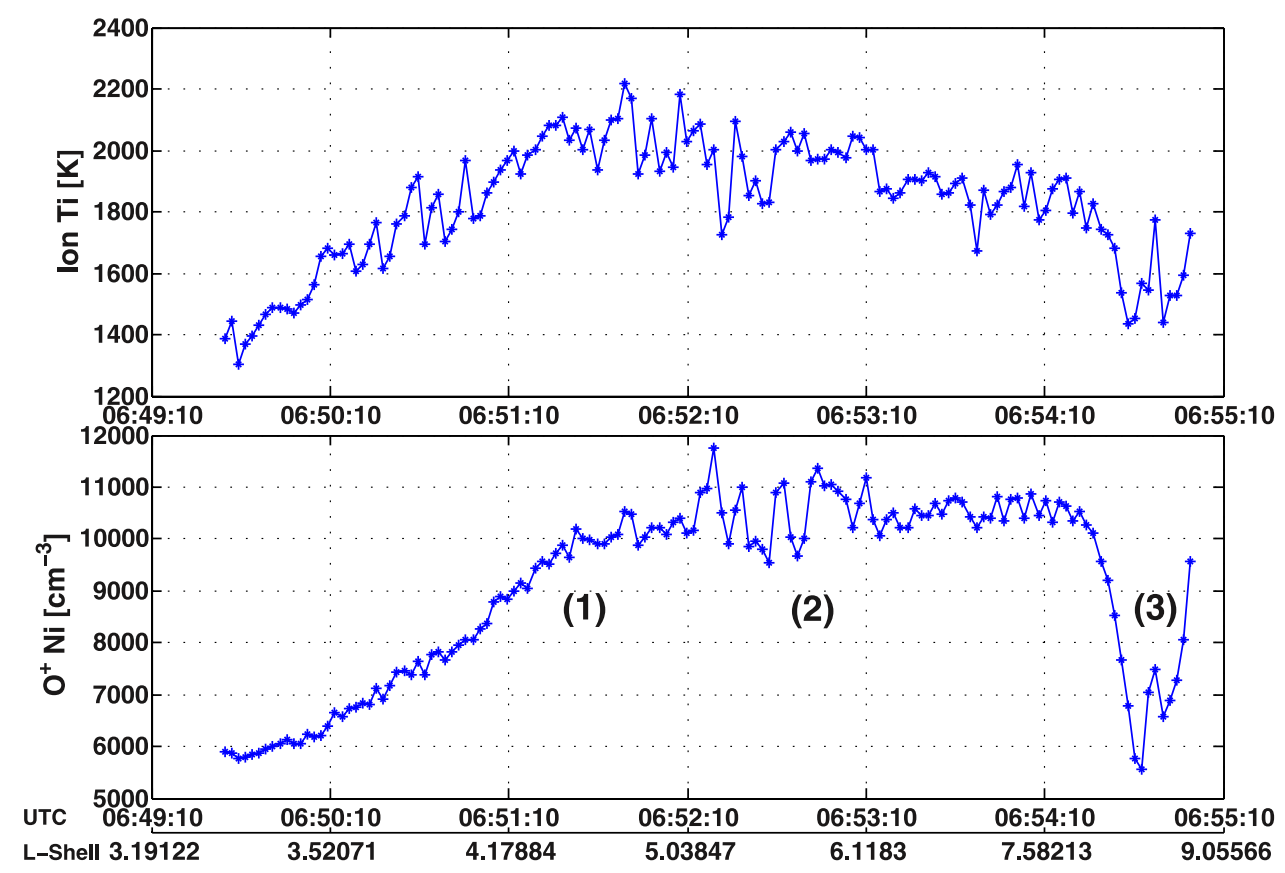

Figure 3. The ion temperature and $\mathrm{O}^{+}$density measured by Demeter at $670 \mathrm{~km}$ during artificial heating $04 / 24 / 07$. The $\mathrm{x}$-axes show the time of the observations, along with the corresponding satellite latitude, longitude and L-shell. HAARP is located at $\mathrm{L}=4.95$. 


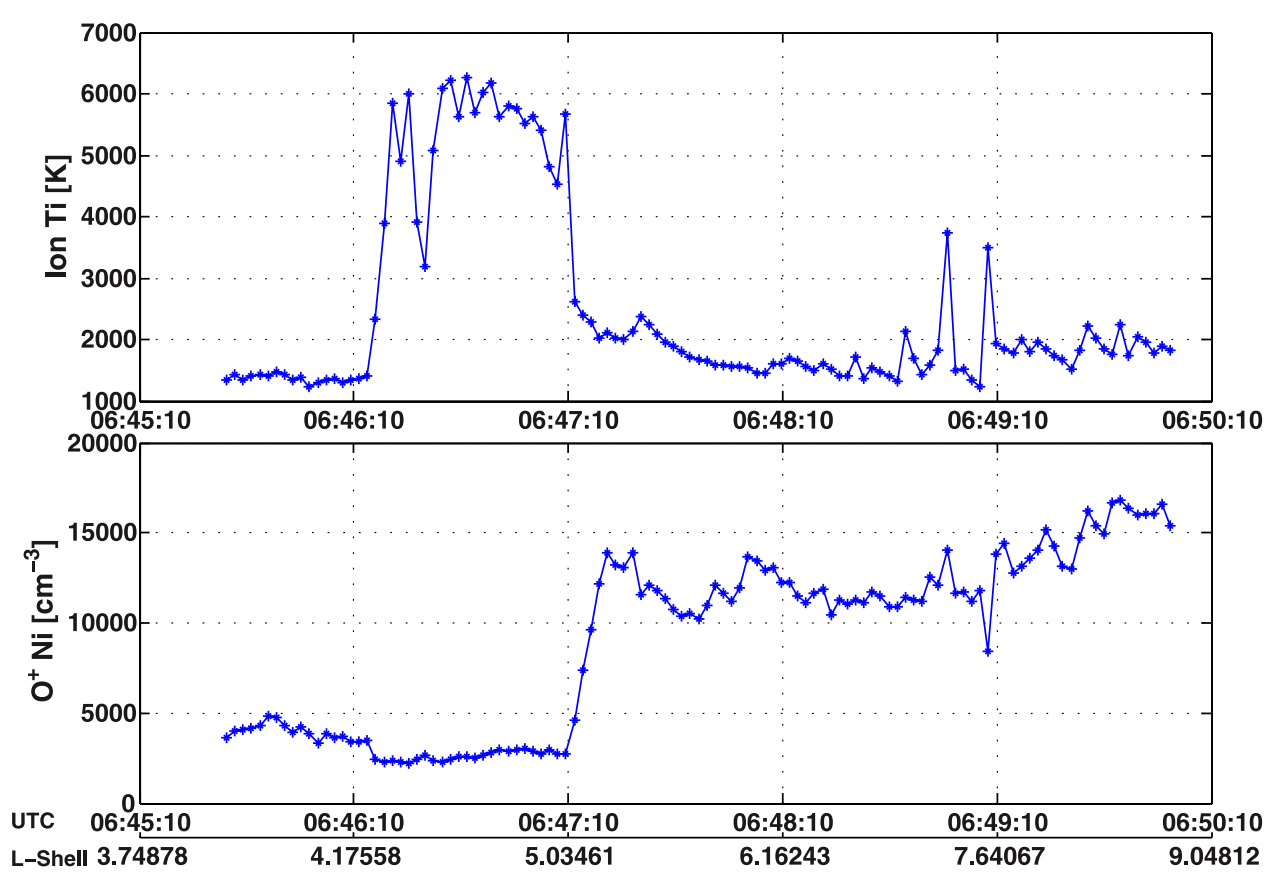

Figure 4. The same as in Figure 3 but measured on 08/01/07.

strong F-region heating which is known to be optimal in a quiet ionosphere with a distinct smooth $F_{2}$ region, and minimal $\mathrm{D} / \mathrm{E}$ region absorption. The ion outflows and density structures are best detected by satellites passing within a few hundred kilometers to the HAARP magnetic field line.

[17] In the frequency range of 3-6 MHz the HF-heated region at $250-270 \mathrm{~km}$ is elliptical with the short axis 60 $80 \mathrm{~km}$ and long axis $80-100 \mathrm{~km}$. The abovementioned spread of the ion outflows by $1,300-1,700 \mathrm{~km}$ is partly due to $\mathrm{E} \times \mathrm{B}$ drifts. In fact, the electric field component perpendicular to the DEMETER orbit is $25-30 \mathrm{mV} / \mathrm{m}$, corresponding to drift velocity directed along the DEMETER orbit in the range $0.4-0.5 \mathrm{~km} / \mathrm{s}$. Since the HF-heating by HAARP starts $10-15$ minutes prior to the DEMETER over-fly the ion outflows spread by about $500 \mathrm{~km}$, which is less than that observed, although some other phenomenon like winds could play a role.

[18] Furthermore the electric field component perpendicular to the DEMETER orbit is in E-W direction, resulting in southward ion drift, i.e. toward the satellite. It accounts for the presence of the spatial asymmetry toward the incoming satellite in Figure 3b.

[19] We should finally comment on the observed shift between the peaks of the perturbed ion temperature and the density of the oxygen ions (see Figure 3). We attribute this to the fact that two different transport mechanisms are involved, as seen in our model. First, the thermal wave caused by the electron heating transfer energy excess to ions. Later on the heating perturbs the electron density at the heating spot. This creates a temporary pressure imbalance which drives the density perturbations along the field line leading to ion outflows.

[20] Our computations reveal that at the heating rate such as produced by HAARP the expected ion temperature increase is approximately $70 \%$ at a distance $400 \mathrm{~km}$ above the heated spot along the field line, while the $\mathrm{O}^{+}$density rises by about $20 \%$. This is in qualitative agreement with the observations. Notice, however, that the version of SAMI2 used here was appropriate to low and mid latitudes. A version of the code which describes high latitudes has been developed at NRL and we are planning to use it in quantitative comparisons with experiments.

[21] Acknowledgments. The work was supported by the ONR grant NAVY.N0017302C60 and by the ONR MURI grant N000140710789. The experimental work was supported by the HAARP Program, Air Force Research Laboratory at Hanscom Air Force Base, Massachusetts, through the ONR contract N00014-02-C0463. We acknowledge CNES for the use of the DEMETER data. We acknowledge Mike McCarrick's expert help in conducting the HAARP experiment and Lee Snyder's supply of the ionospheric diagnostic data. We are thankful to Umran Inan and Denys Piddyachiy for helping us with the Demeter data.

\section{References}

Barr, R., and P. Stubbe (1993), ELF harmonic radiation from the Troms $\varnothing$ heating facility, Geophys. Res. Lett., 20, 2243.

Berthelier, J. J., et al. (2006a), ICE, the electric field experiment on DEMETER, Planet. Space Sci., 54, 456.

Berthelier, J. J., et al. (2006b), IAP, the thermal plasma analyzer on DEMETER, Planet. Space Sci., 54, 487.

Carpenter, D. L., M. A. Spasojević, T. F. Bell, U. S. Inan, B. W. Reinisch, I. A. Galkin, R. F. Benson, J. L. Green, S. F. Fung, and S. A. Boardsen (2002), Small-scale field-aligned plasmaspheric density structures inferred from the Radio Plasma Imager on IMAGE, J. Geophys. Res., 107(A9), 1258, doi:10.1029/2001JA009199.

Duncan, L. M., J. P. Sheerin, and R. A. Benke (1988), Observation of ionospheric cavities generated by high-power radio waves, Phys. Rev. Lett., 61(2), 239.

Ferraro, A. J., H. S. Lee, T. W. Collins, M. Baker, D. Werner, F. M. Zain, and P. J. Li (1989), Measurements of extremely low frequency signals from modulation of the polar electrojet above Fairbanks, Alaska, IEEE Trans. Antennas Propag., 37, 802.

Gurevich, A. V., A. V. Lukyanov, and K. P. Zybin (1996), Anomalous absorption of powerful radio waves on the striations developed during ionospheric modification, Phys. Lett. A, 211, 363.

Helliwell, R. A. (1988), VLF wave stimulation experiments in the magnetosphere from Siple Station, Antarctica, Rev. Geophys., 26, 551. 
Huba, J. D., G. Joyce, and J. A. Fedder (2000), Sami2 is another model of the ionosphere (SAMI2): A new low-latitude ionosphere model, J. Geophys. Res., 105(A10), 23,035.

Inan, U. S., M. Golkowski, D. L. Carpenter, N. Reddell, R. C. Moore, T. F. Bell, E. Paschal, P. Kossey, E. Kennedy, and S. Z. Meth (2004), Multihop whistler-mode ELF/VLF signals and triggered emissions excited by the HAARP HF heater, Geophys. Res. Lett., 31, L24805, doi:10.1029/ 2004GL021647.

Papadopoulos, K., T. Wallace, M. McCarrick, G. M. Milikh, and X. Yang (2003), On the efficiency of ELF/VLF generation using HF heating of the Auroral electrojet, Plasma Phys. Rep., 29, 561.

Papadopoulos, K., T. Wallace, G. M. Milikh, W. Peter, and M. McCarrick (2005), The magnetic response of the ionosphere to pulsed HF heating, Geophys. Res. Lett., 32, L13101, doi:10.1029/2005GL023185.

Parrot, M. (2002), The micro-satellite DEMETER, J. Geodyn., 33, 535.

Perrine, R. P., G. M. Milikh, K. Papadopoulos, J. D. Huba, G. Joyce, M. Swisdak, and Y. Dimant (2006), An interhemispheric model of artificial ionospheric ducts, Radio Sci., 41, RS4002, doi:10.1029/ 2005RS003371.

Shelley, E. G., R. D. Sharp, and R. G. Johnson (1976), Satellite observations of an ionospheric acceleration mechanism, Geophys. Res. Lett., 3 , 654
Streltsov, A. V., M. Lampe, W. Manheimer, G. Ganguli, and G. Joyce (2006), Whistler propagation in inhomogeneous plasma, J. Geophys. Res., 111, A03216, doi:10.1029/2005JA011357.

Stubbe, P., A. J. Stocker, F. Honary, T. R. Robinson, and T. B. Jones (1994), Simulated electromagnetic emissions and anomalous HF wave absorption near electron gyroharmonics, J. Geophys. Res., 99, 6233.

Wahlund, J.-E., H. J. Opgenoorth, I. Häggström, K. J. Winser, and G. O. L. Jones (1992), EISCAT observations of topside ionospheric ion outflows during auroral activity: Revisited, J. Geophys. Res., 97, 3019.

J. J. Berthelier, IPSL, CETP, 4 Avenue Neptune, F-94100 St. Maur, France.

C. L. Chang and T. Wallace, BAE Systems, 1250 24th Street NW, Washington, DC 20037, USA.

G. M. Milikh, K. Papadopoulos, and H. Shroff, University of Maryland, College Park, MD, USA. (milikh@astro.umd.edu)

E. V. Mishin, Institute for Scientific Research, Boston College, 140 Commonwealth Avenue, Chestnut Hill, MA 02467-3862, USA.

M. Parrot, Laboratoire de Physique et Chimie de l'Environnement, CNRS, 3 Avenue de la Recherche Scientifique, F-45071 Orleans CEDEX 2, France. 